\title{
To instill or not to instill - is it still a question?
}

All intubated adults and children managed in an intensive care unit (ICU) require endotracheal suctioning in order to maintain a patent airway. Patients cannot eliminate secretions themselves, partly because the presence of the endotracheal tube (ETT) compromises glottic closure, thereby limiting the pressures and velocity of airflow that can be generated for an effective cough. In addition, normal mucociliary function may be impaired by inadequately humidified inspired gas. The ETT itself may cause irritation of the airways and increased secretion production, and in the presence of respiratory infection the increased amount and viscosity of pulmonary secretionsfurtherimpede clearance..$^{[1,2]}$

Instillation of isotonic saline $(0.9 \%$ sodium chloride) remains common practice in many adult and paediatric ICUs under the impression that the fluid could facilitate the removal of pulmonary secretions by lubricating the catheter, eliciting a cough and diluting secretions. ${ }^{[3,4]}$ However, normal saline instillation for suctioning was first questioned almost two decades ago with clear concerns about efficacy and potential harm. ${ }^{[4]}$ It is in this context that Schmollgruber et $a l^{[5]}$ in this edition of the Journal have attempted to delineate the short-term effects of saline instillation in a sample of South African adult ICU patients who have undergone cardiothoracic surgery.

It is known that mucus and water in bulk form are immiscible and maintain their separate phases even after vigorous shaking. ${ }^{[6]}$ Thus, the function of isotonic saline as a secretion diluent is doubtful at best. Some studies have suggested that sputum yield was greater when using normal saline, but none of these studies took the volume of saline into account when analysing the results. ${ }^{[-9]} \mathrm{Good}$, evidence-based clinical practice suggests that in order to ensure pulmonary secretions are easily manageable with suctioning, adequate humidification of inspired gas is likely to be more effective than instillation of normal saline. ${ }^{[10,11]}$

Previous adult and paediatric studies have consistently reported the adverse effects of saline instillation on arterial oxygenation, ${ }^{[12-17]}$ levels of dyspnoea, ${ }^{[18]}$ and other haemodynamic parameters. ${ }^{[17,19]}$ In Schmollgruber et al., ${ }^{\left[{ }^{[5]}\right.}$ there was a greater decrease in arterial saturation during and after suctioning in the saline instillation group, which persisted for at least 60 minutes. However, it must be noted that this study observed a single suctioning event in a relatively small sample size, so the difference was not statistically significant.

It is not clear whether the deoxygenations that have been reported to occur during suctioning with normal saline instillation were clinically significant. We also do not know whether these short-term observations equate in any way to mid- or longer-term outcomes of ICU care, such as nosocomial infection rates, duration of ventilation, incidence of ETT blockages, survival and quality of life indicators. This requires further rigorously conducted clinical studies with meaningful outcome measures, for which they are adequately powered. ${ }^{[9]}$

It has been suggested that instillation of normal saline in conjunction with endotracheal suctioning may result in dispersion of contaminated adherent material into the lower respiratory tract, with the subsequent increased risk of nosocomial infection such as ventilator-associated pneumonia (VAP). ${ }^{[20,21]}$ The risks of saline instillation on nosocomial infection rates is further supported by the suggested adverse effects of $0.9 \%$ saline on the natural antimicrobial properties of respiratory secretions, which may be damaged by sodium and chloride. ${ }^{[22,23]}$

These suggestions have been supported in a prospective, non- randomised clinical study from China in which not instilling normal saline was associated with a significant decline in VAP rates. ${ }^{[24]}$ Conversely, however, a randomised controlled trial of 162 adult ICU oncology patients (average age 64 years, duration of ventilation 11 days) showed that saline instillation was associated with a significant reduction in the incidence of microbiologically proven VAP, with no difference between groups in atelectasis or ETT occlusion rates. This was attributed to better airway clearance, stimulation of coughing, and a reduction in the ETT biofilm. ${ }^{[25]}$ The results of this study have not been replicated in other ICU populations, and care must be taken when extrapolating evidence from elderly oncology patients with their inherent risk profile relating to immunosuppression, specific antibiotic prescription patterns and baseline rate of nosocomial infection, among other factors. ${ }^{[19]}$

Despite the body of knowledge indicating that instillation of saline is unlikely to be beneficial and may in fact be harmful, ${ }^{[19]}$ and despite the availability of practice guidelines ${ }^{[10,26]}$ that clearly state that routine saline instillation is not appropriate, the practice continues. Shortterm studies such as that by Schmollgruber et al. ${ }^{[5]}$ might suggest that saline instillation is safe to perform in specific groups of ICU patients; however, it would not be appropriate to base practice on such evidence. Rather, we need to look at syntheses of the wider available evidence: these suggest that normal saline instillation may cause or compound haemodynamic complications already associated with endotracheal suctioning, ${ }^{[19]}$ and there is insufficient evidence and no physiological plausibility of benefit in terms of secretion management. There is insufficient evidence in disparate population groups about the benefit or risk in terms of prevention of VAP.

Currently, the balance of evidence is against using normal saline as part of standard clinical practice, ${ }^{[19]}$ but the debate cannot yet be considered closed. There are clearly more questions to be asked and answered regarding the use of saline instillation for endotracheal suctioning. Until we have those answers, through carefully designed clinical research studies, more effort should be made to act on the current evidence-based clinical guidelines ${ }^{[10,26]}$ rather than just paying lip service to them.

\section{B M Morrow}

\section{Editor}

brenda.morrow@uct.ac.za

\section{References}

1. Bailey C, Kattwinkel J, Teja K, Buckley T. Shallow versus deep endotracheal suctioning in young rabbits: Pathologic effects on the tracheobronchial wall. Pediatrics 1988;82(5):746-751.

2. Fisher BJ, Carlo WA, Doershuk CF. Fetus, newborn, child, adolescent. In: Scarpelli EM (editor) Pulmonary physiology. 2nd ed. Philadelphia: Lea \& Febiger, 1990.

3. Roberts FE. Consensus among physiotherapists in the United Kingdom on the use of normal saline instillation prior to endotracheal suction: A Delphi study. Physiother Can 2009;61(2):107 115. [http://dx.doi.org/10.3138/physio.61.2.107]

4. Raymond SJ. Normal saline instillation before suctioning: Helpful or harmful? A review of the literature. Am J Crit Care 1995;4(4):267-271.

5. Schmollgruber S, Bruce J, Rachidi J, Becker PJ. The effect of normal saline instillation on cardiorespiratory parameters in intubated cardiothoracic patients. South African Journal of Critical Care 2014;30(1)):22-27.

6. Demers RR, Saklad M. Minimizing the harmful effects of mechanical aspiration. Heart Lung 1973;2(4):542-545.

7. Bostick J, Wendelgass ST. Normal saline instillation as part of the suctioning procedure: Effects on $\mathrm{PaO}_{2}$ and amount of secretions. Heart Lung 1987;16(5):532-537.

8. Hudak M, Bond-Domb A. Postoperative head and neck cancer patients with artificial airways: The effect of saline lavage on tracheal mucus evacuation and oxygen saturation. ORL Head Neck Nurs 1996;14(1):17-21.

9. Paratz JD, Stockton KA. Efficacy and safety of normal saline instillation: A systematic review. Physiotherapy 2009;95(4):241-250. [http://dx.doi.org/10.1016/j.physio.2009.06.002]

10. Branson RD. Secretion management in the mechanically ventilated patient. Respir Care 2007:52(10):1328-1342. 
11. Branson RD, Campbell RS, Chatburn RL, Covington J. AARC clinical practice guideline: Endotracheal suctioning of mechanically ventilated adults and children with artificial airways. Endotracheal suctioning of

12. Akgül S, Akyolcu N. Effects of normal saline on endotracheal suctioning. J Clin Nurs 2002;11(6):826-830. [http://dx.doi.org/10.1046/j.1365-2702.2002.00655.x]

13. Ji YR, Kim HS, Park JH. Instillation of normal saline before suctioning in patients with pneumonia. Yonsei Med J 2002;43(5):607-612

14. Ackerman MH, Mick DJ. Instillation of normal saline before suctioning in patients with pulmonary infections: A prospective randomized controlled trial. Am J Crit Care 1998;7(4):261-266.

15. Kinloch D. Instillation of normal saline during endotracheal suctioning: Effects on mixed venous oxygen saturation. Am J Crit Care 1999;8(4):231-240.

16. Ridling DA, Martin LD, Bratton SL. Endotracheal suctioning with or without instillation of isotonic sodium chloride solution in critically ill children. Am J Crit Care 2003;12(3):212-219.

17. Celik SA, Kanan N. A current conflict: Use of isotonic sodium chloride solution on endotracheal suctioning in critically ill patients. Dimens Crit Care Nurs 2006;25(1):11-14.

18. O'Neal PV, Grap MJ, Thompson C, Dudley W. Level of dyspnoea experienced in mechanically ventilated adults with and without saline instillation prior to endotracheal suctioning. In Crit Care Nurs 2001:17

19. Caparros AC. Mechanical ventilation and the role of saline instillation in suctioning adult intensive care unit patients: An evidence-based practice review. Dimens Crit Care Nurs 2014;33(4):246-253. [http://dx.doi.org/10.1097/DCC.0000000000000049]
20. Hagler DA, Traver GA. Endotracheal saline and suction catheters: Sources of lower airway contamination. Am J Crit Care 1994;3(6):444-447.

21. Freytag CC, Thies FL, Konig W, Welte T. Prolonged application of closed in-line suction catheters increases microbial colonization of the lower respiratory tract and bacterial growth on cathete surface. Infection 2003;31(1):31-37. [http://dx.doi.org/10.1007/s15010-002-3066-1]

22. Christensen RD, Henry E, Baer VL, et al. A low-sodium solution for airway care: Results of a multicenter trial. Respir Care 2010;55(12):1680-1685

23. Hunter JD. Ventilator associated pneumonia. Postgrad Med J 2006;82(965):172-178. [http:// dx.doi.org/10.1136/pgmj.2005.036905]

24. Mei-Yu L, Shu-Hua C, Yi-Hui S. Reducing ventilator-associated pneumonia (VAP) by not using instillation saline before suctioning [abstract]. Journal of Nursing and Healthcare Research 2012;8(4):325-331.

25. Caruso P, Denari S, Ruiz SA, Demarzo SE, Deheinzelin D. Saline instillation before tracheal suctioning decreases the incidence of ventilator-associated pneumonia. Crit Care Med 2009;37(1):32-38. [http://dx.doi.org/10.1097/CCM.0b013e3181930026]

26. Morrow BM, Argent AC. A comprehensive review of pediatric endotracheal suctioning: Effects, indications, and clinical practice. Pediatr Crit Care Med 2008;9(5):465-477. [http://dx.doi. org/10.1097/PCC.0b013e31818499cc]

S Afr J Crit Care 2014;30(1):2-3. DOI:10.7196/SAJCC.198 